\title{
Heberden Society: Combined Meeting, July 1979
}

A combined meeting of the Heberden Society, the British Association for Rheumatology and Rehabilitation, and the Section of Rheumatology and Rehabilitation of the Royal Society of Medicine was held at Owen's Park, Manchester, on 12-13 July 1979 . The meeting consisted of (1) a symposium on the relevance of contemporary epidemiology to clinical rheumatology; (2) a scientific meeting consisting of 'free' papers selected by the societies; and (3) demonstrations which were intended to augment the scientific communications and to emphasise the shared aims and interests of health professionals and medically related industry.

\section{THE SYMPOSIUM}

The relevance of contemporary epidemiology to clinical practice in rheumatology. ARC Epidemiology Research Unit, University of Manchester (on the occasion of the 25th anniversary of its establishment). Lilienfeld: The epidemiologist attempts to integrate data from diverse disciplines, evaluating the interaction of these factors relative to time, place and person.

Lalonde's new perspective: biological and genetic factors, environmental hazards, life style and behaviour, health care, and the organisation of services.

In considering the health of human populations from these points of view it is customary to follow one or more of Morris's approaches to epidemiology:

\begin{tabular}{ll}
\hline $\begin{array}{l}\text { Classical } \\
\text { Diagnosis }\end{array}$ & $\begin{array}{l}\text { dimensions of disease experience } \\
\text { seeking causes of health and disease } \\
\text { changing pattern of disease }\end{array}$ \\
History & $\begin{array}{l}\text { Recent } \\
\text { Syndromes } \\
\text { Natural history }\end{array}$ \\
$\begin{array}{l}\text { Risk factors } \\
\text { Treatment }\end{array}$ & $\begin{array}{l}\text { completing clinical picture } \\
\text { estimating chances } \\
\text { effectiveness-controlled trials, benefit vs. } \\
\text { risk, etc. }\end{array}$ \\
& efficiency-working of health services \\
\hline
\end{tabular}

The main presentations at the symposium reviewed work appertaining to these considerations, with particular emphasis on relevance for clinical rheumatologists.

Medical characteristics in populations. J. H. Kellgren, Emeritus Professor of Rheumatology. Manchester.

Some of the early studies of chronic rheumatic diseases in populations were described with special reference to the way in which the features of rheumatic diseases as observed in populations differ from those found in patients-especially those attending rheumatism clinics. The import of these findings on clinical practice and on our understanding of rheumatic diseases were diseussed.

Medical characteristics in patients-Identifying syndromes and the diagnostic process. Philip H N Wood. ARC Epidemiology Research Unit, University of Manchester.

Sophisticated epidemiological study of rheumatic disorders is handicapped by a series of generic problems: events are usually ill-defined; states express themselves in variable ways; methodology is cumbersome and blunt; disease concepts are unsatisfactory; causal models are obscure; and information to set the challenge in perspective has been deficient. The implications of these difficulties for research strategies were considered.

A key problem is nosological-rheumatic disorders lack a hallmark, a typical feature or test by which to identify a specific condition. Associated with this are difficulties with illness-disease discordance and heterogeneity. One response has been to assist with clinical studies of natural history-examining the basis on which diagnosis is made, and seeking syndromes within heterogeneous material (juvenile chronic arthritis is the prime example). Disease classification and nomenclature are also relevant, as is variability in geographical expression.

Illness in context-Behavioural characteristics in patients and populations. Michael R. Bury. ARC Epidemiology Research Unit, University of Manchester.

Rheumatology has long been concerned with psychological and social factors. The pioneering work of Sidney Cobb sought to account for the occurrence of RA by examining the family backgrounds of patients. He pointed to a possible link between types of familial experiences and the onset of disease. Despite the fact that this work was limited by its concern with causation, as other workers have 
indicated, interest in psychological and social aetiology remains. In recent years a wider view has emerged, focusing on the disabling consequences of rheumatic disease. Concern has shifted from identifying particular 'personality types' to the problems of chronic illness and rehabilitation, and the resources that individuals are able to call on in adapting to disability. Variations among patients may reflect individual characteristics, whether in handling practical problems or in more sensitive areas such as sexual relationships. However, much variation in the consequences of rheumatic disease may be accounted for by cultural patterning for example in the reaction to pain. Chronic illness typically involves emotional problems and there is a need to complement individually oriented approaches by those stressing the social context, especially the family and wider social network, in which the individual lives.

The challenge for medicine-The consequences of disease; impairment, disability, and handicap. Elizabeth M. Badley. ARC Epidemiology Research Unit, University of Manchester.

When dealing with chronic illness there is usually a limited potential for medical intervention to abolish or reverse the manifestations of the disease process. The challenge is therefore the amelioration of disease consequences. Individual clinical manifestations may give rise to impairment, which in turn can cause disability. These can then lead to disadvantage, or handicap, in all aspects of life.

In assessing the patient the need, then, is to look beyond the immediate clinical findings so as to set them in context. An understanding of the relationship between impairment and disability becomes important in directing therapy to underlying problems, and also provides the opportunity for the development of more focused outcome measures. In particular, monitoring the functional status of patients creates the possibility of evaluation of the long-term effects of disease-course altering drugs. A more comprehensive view of the impact of disease is provided by the concept of handicap, and this can be assessed by a systematic review of the disadvantage experienced in the different dimensions of handicap: orientations, physical independence, mobility, occupation, social integration, and economic self-sufficiency.

Towards a better future-Medical care and the provision of services. Alwyn Smith.

Provision of services to meet the needs of a community is closely analogous to treating an individual patient; it must depend on the most precise possible diagnosis of the specific problem or problems, the setting of specified objectives and the institution of a continuous monitoring of progress and assessment of outcome. Statistical data are as necessary to the provision of such a standard of service to a community as clinical observations are to the treatment of an individual patient. If the statistical data are to be as useful as clinical observations usually are, doctors must accept responsibility for ensuring their quality.

\section{SCIENTIFIC MEETING}

The following papers were presented:

HLA typing in seronegative oligoarthritis. C. J. 은 Eastmond, S. M. Rajah, D. Tovey, V. Wright, Leeds. -

Peripheral arthritis is a well recognised feature of seronegative spondarthritis even when the spinal disease is predominant. The present study was undertaken to determine (1) if histocompatibility (HLA) typing was of the diagnostic value in those patients with seronegative oligoarthritis who lacked. spinal and extra-articular features characterist of this group of diseases, and (2) if HLA B27 positive patients had any distinguishing clinical features when compared with HLA B27 negative patients.

26 (20 male) consecutive patients with a seronegative peripheral oligoarthritis were studied clinically, had an AP pelvic radiograph and were HLA typed. Patients with definite radiological abnormailities of the sacroiliac joints were excluded. Their mean age was $25 \cdot 3$ years (range 9-64). None had more than 6 joints affected at once; 18 had two (12 patients) or one (6 patients) only involved. The lower limb weight bearing joints were most commonly affected $22(84.6 \%)$ patients had a synovitis of one or both knees and $7(26.9 \%)$ had low back or buttock pain and stiffness.

18 patients (14 male) were HLA B27 positive. Two had minor unilateral radiological abnormalities o of the sacroiliac joints. B27 positive and negative patients did not significantly differ with respect of 0 sex ratio, age of onset, number or site of joints $\omega$ affected. Five B27 positive patients gave a past ${ }^{O}$ history, or subsequently developed, extra-articular $\varrho$ features characteristic of seronegative spondarth- $\bar{D}$ ritis, but that did not coincide with the arthritis ? leading to their ascertainment. Two B27 positive males had first degree relatives with ankylosing spondylitis. 
Conclusion. (1) HLA typing may be of diagnostic value in patients with a seronegative oligoarthritis when other features of seronegative spondarthritis are absent. (2) HLA B27 is not associated with any particular clinical features of the arthritis.

Regional differences of HLA antigens in Behcet's disease. H. Yazici, I. Schreuder, H. A. Chamberlain, A. Muftuoglu. Carrahpsa Medical School, University of Istanbul, Turkey; University Hospital, Leiden, Holland; University of Leeds Medical School, England.

Marked regional differences are reported in the association of Behçet's syndrome with HLA B5. ${ }^{2}$ To evaluate these further we have compared the histocompatibility antigens of a group of Turkish patients with a group of English patients in the same tissue typing laboratory (Department of Immunohaematology, University Hospital, Leiden). All patients had $\mathrm{ABC}$ loci typing by the NIH technique utilising antisera against 37 specificities. Bloods from 52 Turkish controls and 34 English controls were similarly typed, typing for B5 subgroups as well as DR typing.

Nineteen Turkish and 14 English patients had DR typing by $B$ cell cytotoxicity utilising antisera against 10 specificities. There were strong associations of $\mathrm{B} 5$ and $\mathrm{Bw} 5 \cdot 1$ with the Turkish patients $(19 / 22$ vs. $22 / 52, \mathrm{P}<0.01 ; 18 / 22$ vs. $12 / 52, \mathrm{P}<0.0005$ respectively). 4/18 English patients and 8/34 English controls carried B5 and/or its subgroups. HLA B27 was raised in the British patients $(4 / 14$ vs. $1 / 34$, $\mathrm{P}<0.05$ (corrected)) (ARR 12.6).

\begin{tabular}{lllll}
\hline HLA & \multicolumn{3}{l}{ Istanbul } & \multicolumn{3}{l}{ Leeds } \\
\cline { 2 - 5 } & $\begin{array}{l}\text { Patients } \\
n=22\end{array}$ & $\begin{array}{l}\text { Controls } \\
n=52\end{array}$ & $\begin{array}{l}\text { Patients } \\
n=14\end{array}$ & $\begin{array}{l}\text { Controls } \\
n=34\end{array}$ \\
\hline *B5 & 19 & 22 & 4 & 6 \\
†Bw5·1 & 18 & 12 & 3 & 4 \\
Bw5·2 & 1 & 10 & 1 & 2 \\
B27 & 1 & 2 & 4 & 1 \\
\hline
\end{tabular}

*Istanbul B5, $\mathrm{P}<0.01$, ARR 8.

†Istanbul B5 $1, \mathbf{P}<0 \cdot 0005$, ARR 16.

\section{References}

1 Chamberlain M A. Ann Rheum Dis 1977; 36: 491.

2 Yazici H et al. Clin Exp Immunol 1977; 30: 259.

HLA antigens, immunoglobulin and complement studies in psoriasis and psoriatic arthritis. T. J. Daymond, M. Thompson. Royal Victoria Infirmary,
Newcastle upon Tyne. J. Bernal, J. Wentzel. Department of Human Genetics, Newcastle University.

Genetic and environmental factors have been implicated in the aetiology of psoriasis and psoriatic arthritis and HLA antigens are known to be associated with immune mechanisms. We have studied HLA antigens, immunoglobulins (Ig), complement factor levels and 3rd component of complement phenotypes to investigate possible differences between the two states of the disease. 48 patients with psoriasis and 60 with psoriatic arthritis (8 with sacroiliitis) were studied. HLA antigen typing was performed by lymphocytotoxicity technique. Ig levels, C3c, C4, and C3 activating factor were determined by radial immunodiffusion. The slow (S) and fast (F) phenotypes of the 3rd component of complement were isolated by high voltage agarose gel electrophoresis.

Results: there was a statistically significant increase in HLA B27 in psoriatic arthritis $(\mathrm{P}<0.025)$ but in no other HLA antigen; 4/8 patients with sacroiliitis were B27 positive. There was a statistically significant increase in IgG $(P<0.002)$, IgM $(P<0.02)$ and $04(P<0.02)$ in patients suffering from psoriatic arthritis irrespective of whether they were B27 positive or negative. Patients with sacroiliitis had a significant increase in IgG, IgE, and decrease in C $3 \mathrm{c}$ compared with the rest.

The distribution of $\mathrm{S}$ and $\mathrm{F}$ phenotypes was comparable in both psoriasis and psoriatic arthritis.

Genetics of ankylosing spondylitis. F. E. Nichol, J. C. Woodrow. Department of Medicine, Liverpool University, England.

Studies of ankylosing spondylitis have been carried out in HLA B27 positive individuals in population samples, in families of patients with the disease and in identical twin pairs.

Radiological evidence of ankylosing spondylitis was found in $20 \%$ of the males and $9 \%$ of the females in the population samples. In the family studies of probands with ankylosing spondylitis $50 \%$ of HLA B27 positive fathers and $5 \%$ of HLA B27 positive mothers had ankylosing spondylitis, illustrating the familial aggregation of the disease. However, studies of identical twins showing discordance for the disease suggests an environmental factor is necessary for the disease to appear.

Analysis of the data suggests that there is an independently segregating gene, in addition to HLA B27, which predisposes to ankylosing spondylitis. 
Tienilic acid. Simultaneous regulation of gout and hypertension. J. A. Reardon, J. T. Scott. Kennedy Institute of Rheumatology, London.

A major problem in the management of gout is control of frequently associated hypertension. Increase in serum uric acid with most diuretics either precipitates acute gout attacks or requires larger doses of uricosurics or allopurinol.

Tienilic acid, a diuretic with uricosuric properties, has been reported to lower serum uric acid levels in hypertension, but its potential has not been previously assessed in gouty patients.

Maintained on a low-purine diet through the 21 days of their admission, 4 patients with gout and hypertension received varying doses of tienilic acid. Detailed measurements were made of urinary uric acid excretion (collected 4-hourly throughout), serum acid uric (8-hourly) plasma and urine electrolytes, fluid balance and resting blood pressure (4hourly).

Serum uric acid fell by an average $4.5 \mathrm{mg} \%$ $(0.27 \mathrm{mmol} / \mathrm{l})$ to values well within the normal range. Urinary uric acid altered little with single daily dosage, but increased significantly with a twice daily regimen. Reduction in diastolic blood pressure was seen in all cases producing an average drop of $22 \mathrm{mmHg}$.

Conclusions: (1) Tienilic acid is a potentially major advance in management of the hypertensive gouty patient. (2) Detailed controlled inpatient studies reveal that twice daily dosage is required for satisfactory reduction in serum uric acid. (3) Single daily dosage caused marked fluctuation in serum uric acid and was frequently associated with acute gout attacks, even in the presence of a normal serum urate level.

Steroid osteoporosis-where does all the calcium go? R. Amos, V. Wright. Leeds and Harrogate.

A patient with rheumatoid arthritis (RA) on corticosteroids (steroids) was turned down for hip replacement on the basis of severe arterial disease characterised by extensive calcification. The pattern of calcification was typical of Mönckeberg's medial arteriosclerosis (MMA), a benign disorder clinically and radiologically distinct from atheroma. The striking changes in the index patient prompted a more thorough investigation of the subject.

The presence of MMA has been sought in pelvic radiographs in 273 patients with a variety of disorders (see Table). In 109 consecutive admissions to a rheumatology hospital, where pelvic radiographs were available, MMA was seen in 7; all 7 were rheumatoid patients who had been receiving long-term steroid therapy. Ninety-one patients attending the Mineral Metabolism Unit at Leeds $\vec{\Rightarrow}$ General Infirmary were reviewed; MMA was pre- $\stackrel{\mathcal{D}}{+}$ sent in 14 patients and was strongly associated with severe osteoporosis whether or not steroid induced. The relationship to steroid therapy was less strong in a group of patients with severe chronic renal $\varnothing$ failure attending a renal unit for dialysis or following in renal transplantation. In itself MMA represents a $\vec{\circ}$ benign complication of steroid therapy though it may indicate the presence of significant bone disease.

\begin{tabular}{|c|c|c|c|c|c|c|}
\hline \multirow[t]{2}{*}{ Diagnosis } & \multirow{2}{*}{$\begin{array}{l}\text { No of } \\
\text { patients }\end{array}$} & \multicolumn{2}{|c|}{ Patients } & \multirow{2}{*}{$\begin{array}{l}\text { Mean age- } \\
\text { years } \\
\text { (range) }\end{array}$} & \multirow{2}{*}{$\begin{array}{l}\text { Mean } \\
\text { duration } \\
\text { of steroid } \\
\text { therapy } \\
\text { years } \\
\text { (range) }\end{array}$} & \multirow{2}{*}{$\begin{array}{l}\text { No. } \\
\text { with } \\
M M A\end{array}$} \\
\hline & & Male & Female & & & \\
\hline
\end{tabular}

\begin{tabular}{|c|c|c|c|c|c|c|c|}
\hline $\begin{array}{l}\text { RA long- } \\
\text { term steroids }\end{array}$ & 26 & 5 & 21 & $\begin{array}{l}62 \\
(42-83)\end{array}$ & $\begin{array}{l}8 \\
(2-21)\end{array}$ & 7 & \\
\hline $\begin{array}{l}\text { RA-no } \\
\text { steroids }\end{array}$ & 23 & 6 & 17 & $\begin{array}{l}58 \\
(27-76)\end{array}$ & - & 0 & \\
\hline $\begin{array}{l}\text { OA and AS } \\
\text {-no steroids }\end{array}$ & 60 & 23 & 37 & $\begin{array}{l}61 \\
(19-95)\end{array}$ & - & 0 & 응 \\
\hline $\begin{array}{l}\text { Steroids for } \\
\text { various } \\
\text { disorders }\end{array}$ & 62 & 23 & 39 & $\begin{array}{l}57 \\
(24-81)\end{array}$ & $\begin{array}{l}9 \\
(1-28)\end{array}$ & 10 & 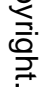 \\
\hline $\begin{array}{l}\text { Spinal } \\
\text { osteoporosis } \\
\text { no steroids }\end{array}$ & 29 & 7 & 22 & $\begin{array}{l}63 \\
(37-77)\end{array}$ & - & 4 & \\
\hline $\begin{array}{l}\text { Chronic renal } \\
\text { failure } \\
\text { (a) On } \\
\text { steroids }\end{array}$ & 37 & 27 & 10 & $\begin{array}{l}34 \\
(18-62)\end{array}$ & $\begin{array}{l}3 \\
(3 / 12-8)\end{array}$ & 7 & \\
\hline $\begin{array}{l}\text { (b) No } \\
\text { steroids }\end{array}$ & 36 & 26 & 10 & $\begin{array}{l}38 \\
(16-58)\end{array}$ & - & 2 & \\
\hline
\end{tabular}

EULAR study of adverse reactions (ARs) to Dpenicillamine (D-P). A. G. L. Kay (for the Standing Committee on International Clinical Studies). ARC Epidemiology and Guy's Arthritis Research Units, Guy's Hospital, London SE1.

Many types of AR to D-P have been reported since $N$ the drug has been used in the treatment of rheumatoid arthritis and allied conditions. 63 centres in 17 member countries monitored 2694 patients $\omega$ treated with D-P between 1 September 1977 and 1 March 1979. All ARs severe enough to require drug withdrawal were reported. The patients were $\bar{\varnothing}$ divided into 2 groups: (1) a prospective sample of $\stackrel{\mathcal{C}}{+}$ all 1410 patients who started to take D-P on or after $\frac{0}{7}$ 1 September 1977 and (2) 1284 patients already taking D-P at the beginning of the study period. 
$18 \%$ of group (1) and $9 \%$ of group (2) had the drug withdrawn because of an AR. $65 \%$ of all group (1) ARs occurred during the first 3 months of treatment when skin rashes, taste impairment, and gastrointestinal disturbances were most common. Renal and haemopoietic abnormalities tended to present later. Multiple ARs were common, less so in those developing renal or haemopoietic complications. Two patients died, 1 with multiple pulmonary abscesses, hemiparesis, and thrombocytopenia, and the other of septicaemia with marrow failure.

It is concluded that a substantial number of serious ARs occur in association with the administration of D-P. Early ARs are more frequent, but serious reactions may occur after many months of treatment. (Note: These are provisional figures, as data still being received).

Comparison of gold, penicillamine, and levamisole in treatment of rheumatoid arthritis. H. A. Capell, J. A. N. Rennie, P. J. Rooney, D. Spencer, W. C. Dick.

Recent multicentre studies ${ }^{2}$ have compared different dose regimens of levamisole in the treatment of patients with rheumatoid arthritis. In view of the potential benefit and toxicity of this drug we consider that data comparing levamisole at different doses with established second-line drugs are urgently required.

Seventy-five patients were randomly allocated to treatment with either gold, penicillamine, or levamisole. The dose of levamisole was $150 \mathrm{mg}$ /day on 3 consecutive days each week and gold and penicillamine were given in conventional dosage. Clinical and laboratory assessments were done at 3 and 6 months.

Of the 25 patients who commenced each drug, 16 remained on gold at the end of 6 months compared with 18 on penicillamine and 9 on levamisole. There was no significant difference in the overall clinical and laboratory response of these patients. Four patients in the levamisole group, all of whom had responded well, developed leucopenia compared with one patient on gold. There was a more rapid drop-out rate on levamisole 3 days/week than in a previous study from this centre using levamisole 7 days/week ${ }^{3}$.

The place of levamisole in the treatment of patients with rheumatoid arthritis requires continuing careful evaluation.

\section{References}

1 Multicentre Study Group. J Rheumatol 1978; 5: Suppl $4,5-10$.

Multicentre Study Group. Lancet 1978; 2: 1007-1012.

8l-Ghobarey et al. Q J Med 1978; 47: 385-400.
A long-term trial comparing ICI 55897 (Clozic) and penicillamine in rheumatoid arthritis. D. Y. Bulgen, B. L. Hazleman, A. M. Mowat, A. G. Mowat. Adenbrooke's Hospital, Cambridge, and Nuffield Orthopaedic Centre, Oxford.

This new compound inhibits the chronic phase of adjuvant arthritis in rats but is essentially devoid of both acute anti-inflammatory and analgesic activity in animal studies. These properties prompted studies in rheumatoid arthritis.

Forty patients with classical or definite rheumatoid arthritis who were taking stable doses of NSAID but required more specific therapy were treated with either penicillamine or ICI 55897 at $100 \mathrm{mg}$ or 300 $\mathrm{mg}$ daily for a period of 6 months. Clinical assessments suggested that ICI 55897 was effective, but less so than penicillamine. Laboratory data showed a similar fall in ESR and acute phase proteins in all groups. Side effects in patients taking $100 \mathrm{mg}$ ICI 55897 daily were nil, suggesting that this drug could provide a safer alternative to gold and penicillamine.

Treatment of fibrosing alveolitis with penicillamine and methotrexate. D. G. I. Scott, R. C. Bucknall, P. A. Bacon. Royal National Hospital for Rheumatic Diseases.

Fibrosing alveolitis (FA) is a well recognised complication of rheumatoid arthritis (RA) and other connective tissue diseases and is thought to relate to circulating immune complexes. Conventional treatment with corticosteroids has been disappointing so alternative drugs, including immunosuppressants, are now being used. The response to penicillamine, which is known to effect systemic RA and immune complexes has not been well documented.

Penicillamine was given to 9 patients with FA followed over a period ranging from 5 months to 4 years. Clinical assessment, chest radiographs and pulmonary function tests were performed before and at regular intervals during treatment. Methotrexate was given to 3 patients with FA, followed over a period ranging from 10 months to 2 years and similarly studied.

Penicillamine had little overall effect (Table). By contrast methotrexate resulted in symptomatic improvement in all 3 patients, radiographic improvement in 2, and significant improvement of lung function in 1 (Table 1). Some improvement in carbon monoxide transfer occurred in all 3 patients compared with improvement of 3 patients treated with penicillamine and deterioration in 6 . Two of the patients treated with methotrexate had deteriorated during previous treatment with penicillamine and 1 
Table Treatment of fibrosing alveolitis with penicillamine and methotrexate

\begin{tabular}{|c|c|c|c|c|c|c|c|}
\hline \multicolumn{4}{|c|}{ 1. D-penicillamine } & \multicolumn{4}{|c|}{ 2. Methotrexate } \\
\hline Diagnosis & Sympt & $C X R$ & $P F T$ & Diagnosis & Sympt & $C X R$ & $P F T$ \\
\hline $\begin{array}{l}\begin{array}{l}\text { Sclero- } \\
\text { derma }\end{array} \\
\text { MCTD } \\
\text { RA } \\
\text { RA } \\
\text { RA } \\
\text { RA } \\
\text { RA } \\
\text { RA } \\
\text { RA }\end{array}$ & $\begin{array}{l}+ \\
\frac{1}{0} \\
- \\
0 \\
0 \\
+ \\
\frac{0}{0}\end{array}$ & $\begin{array}{l}+ \\
0 \\
0 \\
- \\
0 \\
0 \\
+ \\
- \\
0\end{array}$ & $\begin{array}{l}+ \\
0 \\
0 \\
0 \\
0 \\
0 \\
0 \\
0\end{array}$ & $\begin{array}{l}\text { MCTD } \\
\text { DM } \\
\text { RA }\end{array}$ & $\begin{array}{l}+ \\
+ \\
+\end{array}$ & $\begin{array}{l}0 \\
++ \\
++\end{array}$ & $\begin{array}{l}0 \\
+ \\
0\end{array}$ \\
\hline
\end{tabular}

Key - Worse; 0 = No change; + Improved: + + Much improved.

patient had failed to respond to large doses of prednisolone and azathioprine.

Methotrexate may be a useful treatment of severe FA complicating connective tissue diseases and warrants further investigation.

Quantitation of polymorphonuclear (PMN) motility in rheumatic diseases. G. B. Howe, K. V. Swettenham, H. L. F. Currey. Bone and Joint Research Unit, The London Hospital Medical College.

Different techniques of measuring PMN motility have given inconsistent results. We have studied the movement of PMN through Micropore filters using image analysis (Quantimet). This allows projection of a microscopic image on to a television screen and, with appropriate cell staining the instrument 'reads' the proportion of the field occupied by stained cells in focus. This focusing on the upper surface of the filter and then moving stepwise down through the full thickness of the filter provides a profile of cell density distribution through a cylindrical core of the filter. Automation and a linked computer allow rapid analysis of repeated measurements.

Conclusions. (1) $80 \%$ of cells remain within the first $60 \mu \mathrm{m}$ of the filter at 20 minutes. However, a small fraction of cells penetrate the filter much more rapidly, some to drop off the lower surface by 1 hour. (2) Filter thickness varies grossly $(90-280 \mu \mathrm{m}$ within one batch with a stated thickness of $150 \mu \mathrm{m}$ $\pm 15 \%$ ). (3) These considerations indicate that calculations based on filter surface counts are unreliable. Leading front measurements after 20 minute incubations give more reproducible results and correlate well with indices based on measurement of total cell movement. (4) Data obtained using image analysis make it possible to differentiate between total and subpopulation differences.
Polymorphonuclear (PMN) function in rheumatoid arthritis (RA) with and without neutropenia. G. B. $\frac{\square}{\infty}$ Howe, J. N. Fordham, K. A. Brown, H. L. F. Currey. Bone and Joint Research Unit, The London $\stackrel{\bar{s}}{\rightarrow}$ Hospital Medical College.

PMN functions were studied in 29 normal controls $\frac{\bar{D}}{\frac{D}{5}}$ and 25 patients with RA, of whom 9 had persisting $\overparen{\nabla}$ neutropenia (mostly with splenomegaly, i.e., Felty's syndrome).

With a modified Boyden chamber ( $3 \mu \mathrm{m}$ Micro- $\overrightarrow{0}$ pore filters) cell migration was measured by the $\overrightarrow{\vec{\omega}}$ leading front method after 20 minutes' incubation. $\vec{\sigma}$ Both random and directed locomotion were normal in patients with RA alone but significantly impaired in those with RA plus neutropenia. Directed migra- $\infty$ tion was tested in the presence of serum, and all RA sera supported migration as efficiently as did normal of serum, suggesting that this impaired migration reflected a cellular defect. Analysis of the data by computer-linked image analysis (Quantimet) showed that this slowing of the leading front measurement $\mathbb{D}$ was due to an overall showing of all cells rather than depletion of a more mobile subset.

Patients with RA alone had a significant neutro- $\frac{\mathbb{D}}{-}$ philia compared with normal controls. Studies $\mathscr{\theta} \vec{\theta}$ PMN adhesiveness using nylon fibre column co showed the proportions of adhesive to nonadhesiac cells to be the same between all 3 groups. Analysis PMN electrophoretic mobility between these groups showed that all patients with RA had a decrease in

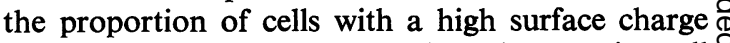
when compared with normals. Changes in cell $\stackrel{2}{\rightarrow}$ migration correlated neither with cell adhesiveness nor with electrophoretic mobility.

\section{Reference \\ 1 MacGregor R B, Spagnuolo P-J, Lentnek A L. $N$ Engl $J$ Med 1974; 291: 642 .}

The incidence of RANA antibodies in rheumatoid arthritis. K. C. Ng, K. A. Brown, J. D. Perry, E. J. Holborow. Bone and Joint Research Unit, London Hospital Medical College, London E1 2AD.

Alspaugh et al. ${ }^{1}$ reported that two-thirds of seropositive rheumatoid patients possess an antibody which gives characteristic immunofluorescent stain- $\tilde{N}$ ing of an antigen termed rheumatoid arthritis nuclear $\mathrm{W}^{N}$ antigen (RANA) present in EB virus transformed human B lymphoblastoid cell lines. We repeatedo their findings using Tan's prototype serum for RANA, and have obtained definite positive tests for $\stackrel{\oplus}{+}$ antibody against RANA with sera from 32 (84\%) of 38 seropositive rheumatoid patients and weakly웅 positive tests in $7(26 \%)$ out of 27 normal subjects. 
A cell line lacking the EB virus genome was negative with all sera tested. All tests were done on coded sera without knowledge of the diagnosis. Sera were also examined for known EB virus antibodies, namely VCA (viral capsid antigen) and EBNA (EpsteinBarr nuclear antigen). We have confirmed that RANA antibodies are independent of these known EB virus antibodies.

\section{Reference}

1 Alspaugh M A, Jenson F C, Rabin H, Tan E M. Lymphocytes transformed by Epstein-Barr virus. J Exp Med 1978; 147: 1018 .

Significance of humoral immunity to native type II collagen in the chronic inflammatory arthritides. R. B. Clague, M. J. Shaw, P. J. L. Holt. Department of Rheumatology, University of Manchester Medical School, Manchester.

Serum IgG and IgM antibody levels to native type II collagen were measured in patients with classical/ rheumatoid arthritis, Still's disease, ankylosing spondylitis and seronegative polyarthritis associated with psoriasis. The results are shown in the Table. The highest levels were found in RA and Still's disease. The 6 patients with elevated IgG antibody levels in the ankylosing spondylitic group all had associated peripheral joint disease.

In the patients with RA, there was a highly significant correlation $(\mathrm{P}<0.001)$ between IgG and IgM antibody levels to native type II collagen. Higher IgG and IgM antibody levels were found to native type II collagen, than native type I collagen. Adsorption studies with denatured and native collagens as well as rabbit IgG, confirmed the specificity of the antibodies to native type II collagen. Most patients with elevated levels had had their arthritis for 4-8 years. The highest levels were associated with severe erosive disease. Similar antibody levels were obtained using bovine, human or rat native type II collagens.

It is suggested that measurement of antibody levels to native collagen, especially type II, may be a useful marker of erosive disease. Sequential studies on patients are in progress and it is hoped to report these at the meeting.

Table Incidence of elevated IgG and IgM antibody levels to native type II collagen

\begin{tabular}{lllll}
\hline & $\begin{array}{l}\text { Rheumatoid } \\
\text { arthritis }\end{array}$ & $\begin{array}{l}\text { Still's } \\
\text { disease }\end{array}$ & $\begin{array}{l}\text { Ankylosing } \\
\text { spondylitis }\end{array}$ & $\begin{array}{l}\text { Psoriatic } \\
\text { arthritis }\end{array}$ \\
\hline Numbers in & & & & \\
group & 33 & 28 & 20 & 14 \\
IgG & 13 & 14 & 6 & 0 \\
IgM & 19 & 10 & 1 & 1 \\
\hline
\end{tabular}

A possible common ancestry for collagen $\alpha A$ and $\alpha \mathbf{B}$ chains. Robert A. Brown, Jacqueline B. Weiss. Department of Rheumatology, University of Manchester.

It is known that at least 4 genetically distinct forms of collagen exist in the connective tissues. Three of these have been completely characterised and the fourth-basement membrane collagen type IV-has been clearly identified. ${ }^{1}$

A new form of collagen consisting of highly glycosylated $\alpha$ chains has been found in rheumatoid and nonrheumatoid inflammed synovial membranes as well as from membranes of normal joints. ${ }^{2}$ There are at present 2 postulated structures for this new collagen either a single molecular association $\left(\alpha \mathrm{A}[\alpha \mathrm{B}]_{2}\right)$ or two separate molecular forms $[\alpha \mathrm{A}]_{3}$ and $[\alpha \mathrm{B}]_{3} .^{3} 4$

The cyanogen bromide peptide patterns which we have obtained support the concept of separate molecular forms. At the same time they show evidence for common ancestry of the two $\alpha$ chains. We further suggest that a third $\alpha$ chain $[\alpha \mathrm{C}]$ may be associated with them and derive from the same source.

\section{References}

1 Miller E J. Mol Cell Biochem 1976; 13: 165-192.

2 Brown R A, Shuttleworth C A, Weiss J B. Biochem Biophys Res Commu 1978; 80: 866-872.

3 Bentz H, Backinger G R, Kuhn K. Eur J Biochem 1979; 92: 563-572.

4 Rhodes R K, Miller E J. Biochemistry 1978; 17: 34423448.

Further studies on diagnostic criteria for polymyalgia rheumatica. H. A. Bird, W. Esselinckx, A. St. J. Dixon, A. G. Mowat, P. H. N. Wood.

An earlier presentation to the Heberden Society in 1978 reported the performance of diagnostic criteria for polymyalgia rheumatica (PMR) in 263 patients who were thought unequivocally to be suffering from this condition. We also mentioned that 70 patients who might possibly have had PMR were also being studied.

These patients with possible PMR have now been followed up after an interval of approximately 3 years. Their clinical status has been assessed, the most likely diagnosis of their original problem has been reviewed in retrospect, and the discriminatory performance of the proposed criteria originally fulfilled has been analysed.

Our proposed criteria were not applied in the possible cases in our original analysis. It is encouraging that, of those fulfilling 3 criteria, the response to a therapeutic test with prednisolone provided very good discrimination. In the largest series of 
cases from one centre, of 15 with 3 criteria 8 had a positive steroid test and all had PMR; 4 had a negative test and on review had RA or OA; and in 3 in whom the test was not done the diagnosis remained uncertain.

We have also explored the value of less stringent models, requiring the presence of only 2 criteria if there was also a response to prednisolone. Once again the results in those with possible PMR were encouraging, although reanalysis of our original data from this point of view does not support the idea that the minimal number of criteria might be reduced other than in very specific circumstances.

Longitudinal studies of circulating immune complexes and acute phase reactants in polymyalgia rheumatica and giant cell arteritis. J. Park, J. G. Jones, B. L. Hazleman. Addenbrooke's Hospital, Cambridge.

The relationship between acute phase reactants, immune complexes, and disease activity was studied in 108 patients with polymyalgia rheumatica and/or giant cell arteritis.

The erythrocyte sedimentation rate (ESR) is the acute phase reactant commonly measured. However, it can be unreliable as an indicator of disease activity. Other acute phase reactants measured were C-reactive protein (CRP), $\alpha$ antitrypsin, orosomucoid, and haptoglobin. Immune complexes were measured by the polyethyleneglycol precipitation complement consumption assay. ${ }^{1}$

$44 \%$ of an active untreated group (21 patients) had increased levels of immune complexes whereas $23 \%$ of an inactive group (49 patients) were raised. They were increased in patients with arteritis.

Detailed longitudinal studies revealed a good correlation between CRP, ESR, and disease activity. It is concluded that the additional measurements of immune complexes and acute phase reactants are no better at reflecting fluctuations in disease activity than the ESR.

\section{Reference \\ 1 Harkiss G D, Brown D C. Clin Exp Immunol 1979; 3.}

The prognosis and management of polymyalgia rheumatica (PMR). J. G. Jones, B. L. Hazleman. Addenbrooke's Hospital, Cambridge.

PMR is considered a benign disease by some ${ }^{1}$ while others $^{2}$ think it is a more serious illness which requires similar treatment to giant cell arteritis. The progress of 85 patients with PMR who presented to a district general hospital has been studied in an attempt to study this relationship.
Thirty-eight patients had PMR alone, 14 developed PMR and GCA within one month. Five patients presented with GCA and then developed PMR and 28 patients developed symptoms of GCA after $\stackrel{?}{\rightarrow}$ presenting with PMR (PMR to GCA). The mean? interval from onset of PMR to onset of symptoms of $\overline{\bar{n}}$ GCA was 1 year (1 month-9 years).

Twenty-two patients $(25 \%)$ developed some $\stackrel{\odot}{\circ}$ cerebral or visual complication (see Table). 15 of these patients were in the PMR-GCA group. Sevenpatients developed complications while on corticosteroids.

Table Cerebral and visual complications in 22 patients with PMR

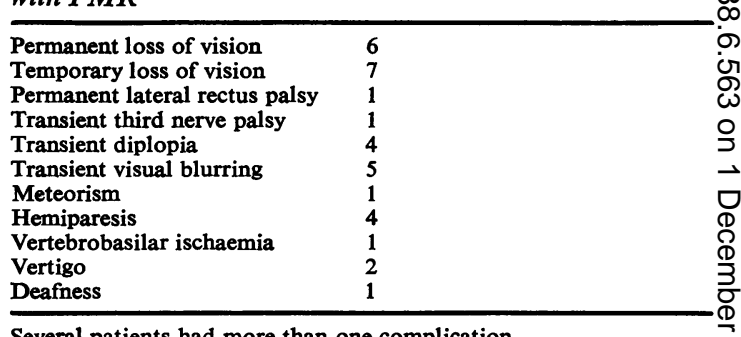

Several patients had more than one complication.

All but 6 patients were treated with corticosteroi果.. Nine patients were able to stop treatment but remainder still require therapy.

In this group of patients PMR appears to result in potentially serious complications in $25 \%$ of patients. Low doses of steroids did not always $\stackrel{\varnothing}{\varnothing}$ prevent these side effects occurring.

\section{References}

1 Ettlinger R E et al. Ann Rev Med 1978; 29 : 15.

2 Hamilton C R et al. Medicine 1971; 50: 1.

Is idiopathic pulmonary hypertension (IPH) ai connective tissue disease? P. J. L. Holt, R. B. Clague, $\rightrightarrows$ F. C. Hay, L. J. Nineham, E. G. Wade. University Department of Rheumatology and Cardiology, Manchester Royal Infirmary, Manchester ando Immunology Department, Middlesex Hospital, London.

Previous papers have suggested that IPH may represent one of the connective tissue diseases. W Twenty-five patients have been studied. In none? was there clinical features of systemic disease and info particular no evidence of rheumatoid disease, SLE ${ }_{\varrho}^{\Phi}$ or systemic sclerosis. Two patients had a positive ${ }^{+}$ Rose-Waaler titre and none had raised anti-DNA $\frac{T}{-}$ antibodies. Thirteen patients with chronic heart disease and pulmonary hypertension and 10 patients $\frac{?}{\mathbb{Q}}$ 
with congenital heart disease and hypertension were examined. A high incidence of immunological abnormalities was found (see Table). The autoantibodies found in the various conditions differed: in IPH they were mainly antinuclear and antithymic; smooth muscle antibodies were only found in patients with congenital heart disease; the patients with rheumatic heart disease had a mixture of autoantibodies. Small quantities of circulating immune complexes were found in all groups.

Table Number of patients with raised values

\begin{tabular}{lcccccc}
\hline & & IgA & IgG & IgGRF & IgMRF & $\begin{array}{l}\text { Auto- } \\
\text { antibodies }\end{array}$ \\
\hline IPH & 25 & 7 & 8 & 16 & 8 & $17^{*}$ \\
SPH & 13 & 9 & 8 & 6 & 5 & 4 \\
CHD & 10 & 5 & 3 & 0 & 0 & 2 \\
\hline
\end{tabular}

*All these 17 patients had two auto-antibodies. IgGRF and IgM RF by radioimmunoassay. IPH=idiopathic pulmonary hypertension. SPH = secondary pulmonary hypertension. $\mathrm{CHD}=$ congenital heart disease.

Rheumatoid factors of both IgG and IgM type were raised in patients with both IPH and hypertension secondary to rheumatic heart disease but not when congenital heart disease was the cause of pulmonary hypertension. From these studies no clinical evidence of a generalised systemic disease, such as is found in the unusual types of connective tissue disease has been found in IPH. But there is strong evidence of an immunological basis for this disease, and this may offer hope of a method of treatment for this usually fatal disease.

OA-Should the patient lose weight? Elvet E. Smith, Philip N. H. Wood, ARC Epidemiology Research Unit, University of Manchester.

A patient presenting with pain in the knees and evidence of osteoarthrosis (OA) is usually advised to reduce weight. The scientific basis for this advice is particularly the work of Kellgren and Lawrence, ${ }^{1}$ who demonstrated a relationship between assessments of obesity and the overall severity of radiographic changes in OA. However, the association is not observed in all populations, and some clinicians have expressed doubts about the link.

In order to explore this association further we have reviewed data from a larger sample-the original report was based on those aged 55-64, and cohort effects might have been observed. The radiographs were reread so as to distinguish between osteophytosis and evidence of joint damage in the different compartments of the knee. Obesity was assessed by the more sensitive Quetelet's (Q) index (weight $\div$ height $^{2}$ ).
Because different observations have been made one would expect the results to differ also. Just as the pattern of distribution with age is different between osteophytosis and joint narrowing, so their relationship with degrees above or below the $\mathbf{Q}$ index mean for age varies as well. When the differences between medial and lateral compartments are taken into account the associations become far more complex. Although dispatching a patient with one problem, painful knees, after inflicting a second problem, dieting, may promote relief of symptoms, the aetiological significance of obesity in regard to OA knees is far from straightforward.

\section{Reference \\ 1 Kellgren J H, Lawrence J S. Ann Rheum Dis 1958; 17: 388.}

Measurement of quadriceps muscle wasting. A. Young, I. Hughes, P. Russell, M. J. Parker. Oxford Rehabilitation Research Unit.

It is difficult to obtain an objective measure of the size of an individual muscle. In a needle biopsy study of quadriceps wasting following lower leg fracture and subsequent knee immobilisation ${ }^{1}$ measurements of muscle fibre size suggested that quadriceps wasting might sometimes be much greater than would be expected from anthropometric estimates of fatfree thigh volume.

Grey-scale ultrasonography can produce an image of the quadriceps muscle from which it is possible to measure its cross-sectional area (CSA). The between-days coefficient of variation for quadriceps CSA (at mid-thigh) in 14 legs of 7 subjects each scanned on 4 days was reduced to $4.0 \%$ by averaging 4 scans on each day.

Bilateral scans at the mid-thigh level were used to measure the severity of quadriceps wasting in otherwise healthy adult patients with at least $2 \mathrm{~cm}$ discrepancy in thigh circumference following unilateral knee immobilisation or injury. Quadriceps wasting as demonstrated by the scans was consistently more severe than the disparity in thigh crosssectional area at the same level or the disparity in anthropometric estimates of fat-free thigh volume. The extent to which measurements of thigh circumference may underestimate the severity of quadriceps wasting must be recognised if clinical measurements are to be correctly interpreted.

\section{Reference}

1 Sargeant A J, Davies C T M, Edwards R H T, Maunder C, Young A. Clin Sci Molec Med 1977; 52: 337-342. 
Profile of rheumatic disabilities. Elizabeth M. Badley, Michael R. Bury, Philip H. N. Wood. AR Epidemiology Research Unit, Manchester.

A lengthy enumeration of disabilities present can be daunting for all concerned. For research purposes Guttmann scaling has been used for simplification, with the assumption that activities can be ordered so that inability to perform one would imply inability with those further up the scale. However, this empirical approach offers little to the clinical teamthey cannot avoid all the diverse individual problems and the implication that each need should be met.

The interrelationship between various disabilities can be approached in other ways. We have studied the range of disabilities in individuals with RA, $\mathrm{OA}$, and back troubles, using these as models for polyarticular, monarticular, and spinal involvement in the light of clusters of activities identified previously. ${ }^{1}$ Comparison between the groups highlighted the dominant influences of age and sex and of features associated with these, such as living alone. After allowing for these we have explored the interdependence of different disabilities.

The patterns of disabilities were much as would be expected on the basis of clinical experience and the features of the underlying conditions. However, the attempt to display regularities in these relationships has proved instructive. The results suggest ways in which the process of assessment might be simplified, with potential implications for clinical practice as well as research.

\section{Reference}

1 Badley E M, Lee J, Wooh P H N. Rheumatol Rehabil 1979; 18: 105.

Antirheumatic drug treatment of outpatients: a tolerance study. A. Kay, R. Jacoby, M. I. V. Jayson. University of Bristol and the ARC Epidemiology and Guy's Arthritis Research Units, Guy's Hospital, London SE1.

A pilot study suggested that discontinuation of drug treatment was common among rheumatic patients. $119(3 \%)$ of the patients attending the rheumatology clinics at Bristol Royal Infirmary, between 1 April 1976 and 1 February 1977, had their drug therapy added to or changed. There were 49 males and 71 females, mean age 47 years: two-thirds of the patients were receiving treatment for rheumatoid arthritis or other inflammatory arthropathies.

The patients were registered and the details of their drug treatment recorded. Within 3 months of starting the new treatment (index drug(s)) eacton patient was submitted to a written questionnaire clinic follow-up of treatment outcome was also main tained for 1 year.

123 index drugs were prescribed and by the en of the year only $36(29 \%)$ of them were still being taken. 41 of the drugs had been stopped during the first 3 months nearly half of these because of the adverse effects. Eight drugs accounted for over $90 \%$ of index prescribing: corticosteroids were not used:The drugs most commonly used were indomethacin $\vec{w}$ ibuprofen, and naproxen. Half the patients on gols and penicillamine and a quarter of those on indo methacin developed adverse reactions.

Observations made in one rheumatology clinig showed adverse reactions to be the commonesi cause of drug withdrawal. The range of drugs usedw was small.

Survival in rheumatoid arthritis. John E. Zlosnik Philip H. N. Wood, ARC Epidemiology Researchn Unit, Manchester.

An earlier 20 year follow-up of 189 Harrog patients with $\mathrm{RA}^{1}$ demonstrated that in both sefes and at all ages mortality was higher than in the general population of England, and that this was correlated with the initial grade of functionab impairment However, deaths from the individua $B$ causes were too few to establish satisfactorily an $\overrightarrow{\mathrm{S}^{\circ}}$ excess or deficit of particular diseases.

Because of the theoretical interest of positively and negatively associated conditions (including. suggested deficits of myocardial infarction and excesses of infection and renal disease), an attemp has been made to augment these data by 20 yeas follow-up of 252 Hammersmith patients (Bywaters) and 307 Edinburgh patients (Duthie).

The results permit calculation of the degree of under-reporting of RA on death certificates, which allows overall prevalence estimates to be generated from routine mortality statistics. The generallye reduced chances of survival in RA were confirmed $N$ as were various features associated with an unfavour able outcome.

Even with this large series of cases there is difficulty in assessing the significance of the asso? ciation of certain causes of death (e.g., suicide)은 This material is useful as a reference standard fore comparison with groups of patients, either with ${ }^{\text {? }}$ particular features or submitted to various forms of treatment. The most important limitation is tha? this experience is not representative of today's? 
patients, but this is unavoidable and important lessons can nevertheless be learned.

\author{
Reference \\ 1 Benn R T, Wood P H N. Br J Prev Soc Med 1972; 26: 60.
}

The long-term management of early rheumatoid arthritis. R. Million, J. H. Kellgren, P. H. Poole, M. I. V. Jayson. Department of Rheumatology, University of Manchester.

We have completed a long-term study over 10 years comparing 2 different philosophies of treatment for early definite and classical arthritis. In the first (group I) the patients were kept mobile avoiding rest and splintage but using nonsteroidal antiinflammatory drugs (NSAID), specific antirheumatic agents, and the responsible administration of systemic prednisolone up to $20 \mathrm{mg} / \mathrm{day}$. The second (group II) received conservative treatment with rest, splints, NSAID, and specific antirheumatic agents but excluding the use of systemic steroids. If the disease was inadequately controlled the patients were transferred to a common regimen involving both forms of treatment. 103 patients were entered (53 group I, 50 group II). After 10 years only 24 remained in group I ( 9 on steroids, mean dose 9.5 $\mathrm{mg} /$ day) and 22 in group II. Thirty-seven patients in all received steroid therapy.

In the majority of parameters the patients remaining in group I were better than in group $I$ and in several of these the differences achieved statistical significance. Seven of the group I patients died (2 steroid related, 0 disease related) and 8 of group II ( 0 disease related 1 treatment related). Four patients, 2 from each group, suffered vertebral body collapse, but all had severe disease, had failed the initial treatment programmes, and were in the final common regime. Other side effects of treatment were comparable in the 2 groups. The patients who failed the 2 regimens ended up receiving similar forms of treatment. At the end of 10 years the clinical and laboratory parameters in these patients were very similar.

We conclude that maintenance of physical activity combined with the responsible use of steroids when necessary may be regarded as a useful form of treatment in early rheumatoid arthritis.

Unusual collagenase and gelatinase enzymes in immature pig intervertebral discs. Ian Tomlinson, M. I. V. Jayson, Jacqueline B. Weiss. Rheumatic Diseases Centre, University of Manchester.

A collagenase capable of attacking the helical portion of the collagen molecule has been demonstrated from day 1 in both annulus and nucleus of pig intervertebral disc. Unlike normal mammalian collagenases this enzyme is not inhibited by EDTA. On the contrary concentrations of 5 mM EDTA and over actually enhance the activity. The enzyme is present in the free form but it can be activated by mersalyl, suggesting it is also present as an enzyme inhibitor complex. When EDTA and mersalyl are added together to the incubation mixture, the activation by mersalyl is further enhanced.

Enzymes capable of acting on a gelatin substrate are also present in the annulus of discs from day one but cannot be detected in the nucleus of corresponding discs. These enzymes are always present in the active form and treatment with mersalyl tends to mildly inhibit. Treatment with EDTA activates one of those enzymes and inhibits another.

Identification of collagenase and other neutral proteinases in human intervertebral discs. S. K. A. Sedowofia, I. Tomlinson, M. I. V. Jayson, Jacqueline B. Weiss. Rheumatic Diseases Centre, University of Manchester.

Collagenolytic enzymes have been directly extracted from human intervertebral disc by a method which partially denatures the collagen matrix. ${ }^{1}$ These enzymes have been detected and identified in crude mixtures by means of an assay system which employs specific substrates carrying a tritium label. ${ }^{2}$

At least 2 neutral proteinases in addition to collagenase have been detected. The collagenase is inhibited by EDTA but not to any significant extent by cysteine. It is present in a free form as well as in an enzyme-inhibitor complex which can be activated by mersalyl. In contrast other thiol blocking agents such as PCMB inhibit the enzyme slightly. A neutral proteinase with high activity against a gelatin substrate is present in free as well as in a zymogen form but is not apparently present as an enzyme inhibitor complex.

Free endogenous inhibitors of neutral porteinase activity have also been demonstrated in disc tissue.

\section{References}

1 Weeks J C, Halme J, Woessner J F. Biochem Biophys Acta 1976; 445: 205-214.

2 Weiss J B, Sedowofia K A, Jones C. In: Viidik A, Vuust J, eds. The Biology of Collagen. New York: Academic Press, in press.

Is there an autoimmune basis for lumbar disc disease? M. De Silva, B. Hazleman, M. Ward, J. Park, I. Dixon. Addenbrooke's Hospital and Strangeways Laboratories, Cambridge. 
After embryological development the nucleus pulposus (NP) is enclosed within the annulus fibrosus (AF) and from an immunological viewpoint has been considered to be a sequestered antigen. Rupture of the AF and posterior longitudinal ligament occurs in the prolapsed intervertebral disc (IV) syndrome, exposing the NP to immunocompetent cells. Several authors have considered autoimmunity as a possible aetiological factor ${ }^{\mathbf{1}}$ in lumbar disc disease, and others believe that autoimmunity could contribute to the chronicity of symptoms. ${ }^{2}$ If valid, these concepts could have important diagnostic therapeutic and prognostic implications.

The purpose of our study was to investigate the possible existence of an autoimmune basis. Twenty patients with prolapsed lumbar IV discs with positive myelograms, who were subsequently treated surgically and an equal number of age and sex-matched controls were studied. Soluble antigens were prepared from IV discs obtained from a fresh young human cadaver. Lymphocyte transformation, immunoglobulin quantitation, C-reactive protein and ESR were performed. Our results showed no significant differences in any of the above indices between patients and controls. We were unable to confirm by our methods the existence of an autoimmune basis for intervertebral disc disease.

1 Naylor A. The biophysical and biochemical aspects of intervertebral disc herniation and degeneration. Ann $R$ Coll Surg Engl 1962; 31 : 91.

2 Gertzbein S T, Tait J H, Devlin S R. Clin Orthop 1977; 123: $149-154$.
}

Annular tears in the dorsolumbar spine (D10-L5). R. C. Hilton, J. Ball, R. T. Benn. Department of Rheumatology, University of Manchester and Hope Hospital, Salford.

The distribution and severity of anterior and posterior annular tears in the dorsolumbar spine have been studied in 52 female and 65 male postmortem spines (aged 13-96 yr) using sagittal slabs of the discs and vertebral bodies. The findings were correlated with angular sagittal mobility.

Results: (1) The number of cases with tears in multiple discs increases with age but exceptions to this trend occur in both young and elderly spines. (2) Correlation coefficients indicate that anterior and posterior tears at L4 and L5 do not predict tears at other levels. At L3 and above significantly positive correlations occur between multiple disc levels particularly posteriorly. (3) The severity pattern for anterior and posterior annular tears differs with respect to age in cases $>50$ yr. the mean anterior tear score rises sharply from L5 to peak at L2 and
$\mathrm{L} 1$ in both sexes; in contrast the mean posterior tear score falls from L4 to L1 in this age group. (4) The increase in severity of anterior tears corres ponds with increased mobility in L4-L1 discs from 50-70 yr. In contrast mobility of the L5 disc falls progressively with age.

Conclusions. The data are compatible with $\frac{20}{20}$ factors causing tears posteriorly one affecting $L 4$ and L5 in young adults, and a second operating at as later age and promoting widespread disc involve? ment. The increased prevalence and severity of anterior tears (and the associated increase in mobility) in the upper lumbar region in the middle aged and elderly may be a pathogenic factor in back pain for this age group.

Computed tomography of the lumbar spine. N. $M_{0}^{\mathrm{\omega}}$ Antoun, I. Isherwood, K. H. Nilsen, M. I. V? Jayson. Departments of Diagnostic Radiology and Rheumatology, University of Manchester.

Computed tomography (CT) is an $x$-ray transmission technique providing transaxial sections approxi mately $1 \mathrm{~cm}$ in thickness. The method permits the demonstration of spinal topographical anatogne against a detailed background of paravertebiap structures and body cavity organs. In particulas enables precise identification of apophyseal joint to be made together with their relationship to thछ spinal canal and the intervertebral foraminae. Ovef 3000 patients have been investigated on the EMD CT5005 General Purpose Scanner in the Depart ment of Diagnostic Radiology, University o\$ Manchester Medical School, since 1976. The spine has been imaged in all patients but particulap attention has been directed to some 300 patients presenting with spinal disorders. Computer assiste $\bar{\phi}$ myelography with a water-soluble contrast mediur? (metrizamide) has been employed in the demont stration of neural tissue and the pathological pro@ cesses affecting it. The movement of metrizamide in neural tissue has been explored. Current researc? is directed towards the value of higher resolution and reduced section thickness in the demonstration of neutral tissue without contrast medium. The applin cation of the technique in the study of a variety of structural disorders will be discussed and illustrate CT is particularly valuable in identifying and localiso sing spinal canal stenosis and apophyseal join disease. The digital nature of the image allows access to the quantitative study of trabecular bone. Thø anatomical configuration of the spine together with restricted section thickness at present place con straints on the role of CT as a screening procedure in the investigation of spinal disorders. 


\section{DEMONSTRATIONS}

The mouth in connective tissue disease. Derek Chisholm, Gabriel Donald. Glasgow Dental School and Department of Medical Illustration, Western Infirmary, Glasgow.

Soft tissue release of hips and knees in juvenile chronic arthritis. M. Swann, N. Rowden, B. M. Ansell, D. Macauley. Juvenile Rheumatism Unit, Canadian Red Cross Memorial Hospital, Taplow, Berks.

Conservative treatment of the hip in juvenile chronic arthritis. M. Swann, B. M. Ansell. Juvenile Rheumatism Unit, Canadian Red Cross Memorial Hospital, Taplow, Berks.

Amyloidosis in juvenile chronic arthritis. B. M. Ansell, A. Howard, M. Gwyther. Clinical Research Centre, Northwick Park Hospital, Harrow, Middlesex.

Hind foot involvement in juvenile chronic arthritis. B. M. Ansell, A. B. Kinnier Wilson. Juvenile Rheumatism Unit. Canadian Red Cross Memorial Hospital and Clinical Research Centre, Watford Road, Harrow.

The adolescent learning to live with arthritis. Juvenile Rheumatism Unit, Canadian Red Cross Memorial Hospital, Taplow, Maidenhead.

Frequency of chondrocalcinosis of the knees and avascular necrosis of the femoral heads in gout. J. T. Scott, A. Stockman, L. G. Darlington. Kennedy Institute of Rheumatology, London.

The Northwick cervical collar. S. A. Peskett, K. Laming, R. Roberts, B. M. Ansell, D. S. Smith. Division of Rheumatology, Northwick Park Hospital Harrow, Middlesex.

ARC national cash register of less common rheumatic diseases. Hilary Hill, W. Carson Dick, Philip H. N. Wood, Verna Wright.

Postgraduate aids in rheumatology. J. Ferguson. WB Pharmaceuticals Ltd., Bracknell, Berks.
Processing results from a medical survey. April Kay, Clinical Section, David Hewitt, Data Processing Section; ARC Epidemiology Research Unit, University of Manchester.

Fibrogenesis imperfecta ossium-the seventh case. J. Ball, J. Denton, W. van't Hoff, C. Jones, A. J. McCall. North Staffs Royal Infirmary and Department of Rheumatology, Manchester University.

The surveillance of work factors in relationship to low back pain in industry. J. A. D. Anderson, B. J. Sweetman, P. Kiernan. Department of Community Medicine, Guy's Hospital, London.

The action of drugs on the release of prostaglandins and lysosomal enzymes from stimulated mouse peritoneal macrophages. N. Skeldon, L. Steele. Research Department, Boots Company Limited, Nottingham.

Impairment, disability, and handicap. Philip H. N. Wood, Elizabeth M. Badley, Michael R. Bury. ARC Epidemiology Research Unit, University of Manchester.

Gout-A historical disease. M. S. Dixon. Medical Division of the Wellcome Foundation Ltd.

Adverse drug reactions to pyrazole drugs. P. D. Fowler. Medical Department, Geigy Pharmaceuticals.

A neutral collagenolytic system from inflamed synovial membranes. Jacqueline B. Weiss, S. K. A. Sedowofia, C. Jones. Department of Rheumatology, University of Manchester.

Angiogenesis and its relevance to inflammatory arthritis. Robert A. Brown, Jacqueline B. Weiss. Department of Rheumatology, University of Manchester.

\footnotetext{
References

1 Folkman J. Sci Am 1978; 59-73.

2 Philips P, Kumor S. Int J Cancer 1979; 23: 82-88.
}

Intra- and periarticular injection techniques. Medical Department, Upjohn Limited. 
Computerised diagnostic index. David Hewitt, Premlata Gandhi, Karla Brabbins. Data Processing Section, ARC Epidemiology Research Unit, Univerisity of Manchester.

Needle biopsy of muscle in clinical practice. R. H. T. Edwards, ${ }^{1}$ C. A. Maunder, ${ }^{2}$ J. M. Round, ${ }^{1}$ C. M. Wiles, ${ }^{1}$ A. Young. ${ }^{3}{ }^{1}$ University College Hospital Medical School, ${ }^{2}$ Jerry Lewis Muscle Research Centre, Hammersmith Hospital, and ${ }^{3}$ Oxford Rehabilitation Research Unit.

Epidemiological Services. ARC Epidemiology Research Unit, University of Manchester.

Human immunity to native type II collagen in human arthritis. R. B. Clague, M. J. Shaw, P. J. L. Holt. Department of Rheumatology, Manchester Royal Infirmary.

Humoral immunity in native type II collageninduced arthritis in the rat. Keith Morgan, Roy B. Clague, Mary J. Shaw, P. J. Lennox Holt. Depart- ment of Rheumatology, University of Manchester Medical School, Oxford Road, Manchester M13 9PT.

Intra-articular therapy and arthritis: Suggested $\frac{\overline{ }}{\bar{D}}$ techniques of injection for Lederspan (triamcinolone $\frac{\bar{\sigma}}{\sigma}$ hexacetonide). Medical Department, Lederle Labo-ฉ ratories, Fareham Road, Gosport, Hampshire.

Rheumatoid arthritis: A patient's viewpoint. G. Poole, E. W. Paice. Stoke Mandeville Hospital, Aylesbury.

Arthritis and everyday life. Michael R. Bury. ARC Epidemiology Research Unit, University of Manchester.

Everyday life of children with arthritis. Gerald Beales. Department of Rheumatology, University of Man- $\mathbb{\AA}$ chester.

Designing a field survey. ARC Epidemiology Researo Unit, University of Manchester. 